\title{
An unusual cause of Grade Illb Clavien complication of percutaneous nephrolithotomy: Broken and retained Malecot nephrostomy catheter
}

\author{
Bora Ozveren, MD; Ahmet Sahin, MD \\ Department of Urology, Acibadem University School of Medicine, Turkey
}

Cite as: Can Urol Assoc J 2016;10(3-4):E122-4. http://dx.doi.org/10.5489/cuai.3285

\section{Abstract}

Percutaneous nephrolithotomy (PCNL) is a relatively safe operation with low rates of major complications. Clavien-Dindo classification is a validated system to record complications, although still needing standardization in reporting and scoring of complex and rare events. We report an unusual adverse incident that required interventional management and impacted the postoperative course.

The case of a broken re-entry Malecot nephrostomy catheter as it was being removed on the third postoperative day of an otherwise uneventful PCNL is described. The retained part was removed by open-surgery under general anesthesia. This incident has upgraded the minimally invasive surgery to a Grade IIIb complicated procedure according to the modified Clavien classification. Patient data, procedure conditions, and surgical retrieval of the catheter are detailed.

Although far from being life-threatening, this rare complication due to a broken and retained drainage catheter is regarded as a high-grade complication according to the Clavien system.

\section{Introduction}

Complications of percutaneous nephrolithotomy (PCNL) causing deviation from the normal course can occur during creation of access, calculi treatment, or during the postoperative period. Major complications of Grade III and higher according to modified Clavien-Dindo (MCD) system are uncommon. ${ }^{1}$ Nevertheless, the definitions and management still lack consensus and several authors have attempted to assess and classify PCNL complications in a consistent manner. ${ }^{2}$ In order to strengthen the validity and reliability of the MCD system in PCNL, data on management of rare complications should be reported.

We report the case of a broken re-entry Malecot nephrostomy catheter that was retrieved by open surgery. This unprecedented complication in an otherwise uneventful
PCNL operation inevitably categorized the case as Grade IIIb complicated, according to the recent assignment of MCD scores. $^{3}$

\section{Case report}

A healthy, 35-year-old man underwent PCNL with a diagnosis of multiple calculi sized $8-18 \mathrm{~mm}$, impacted in the bifid pelvis of left kidney with hydronephrosis in the upper collecting system (Fig. 1). In prone position under general anesthesia, superior calyceal system was punctured in the intercostal space and progressively dilated until 30F Amplatz sheath was placed. All calculi were fragmented and extracted. Final nephrostogram displayed no significant extravasation of contrast fluid. Amplatz sheath was withdrawn and a 16F re-entry Malecot nephrostomy catheter was inserted with the "wing" positioned at the pelvis.

The postoperative period was also uneventful, and chest $X$-ray showed no hydropneumothorax. The urine was clear and the amount coming from the nephrostomy decreased on the second day (when the tube was clamped) and the patient had no complaints of pain or fever thereafter. The next morning, as the nephrostomy was removed in the patient's room, the tube came out broken. The retained part of the tube wasn't visible upon initial examination. X-ray showed that the distal edge of the broken tube was far from the subcutaneous plane. A non-contrast computed tomography (CT) revealed the "wing" part of the nephrostomy tube engaged inside the parenchyma, with the $6 \mathrm{~F}$ tip still in the ureter and the edge of the broken shaft trapped at the intercostal space (Figs. 2, 3). Then, the patient began having acute severe pain and a shared decision of open surgical retrieval of the broken nephrostomy catheter was settled upon with the patient's informed consent.

The patient was placed in lateral decubitus flank position under general anesthesia. The access site was lengthened to a $4 \mathrm{~cm}$ incision. Exploration revealed the edge of the retained catheter at the retroperitoneal perirenal space and 


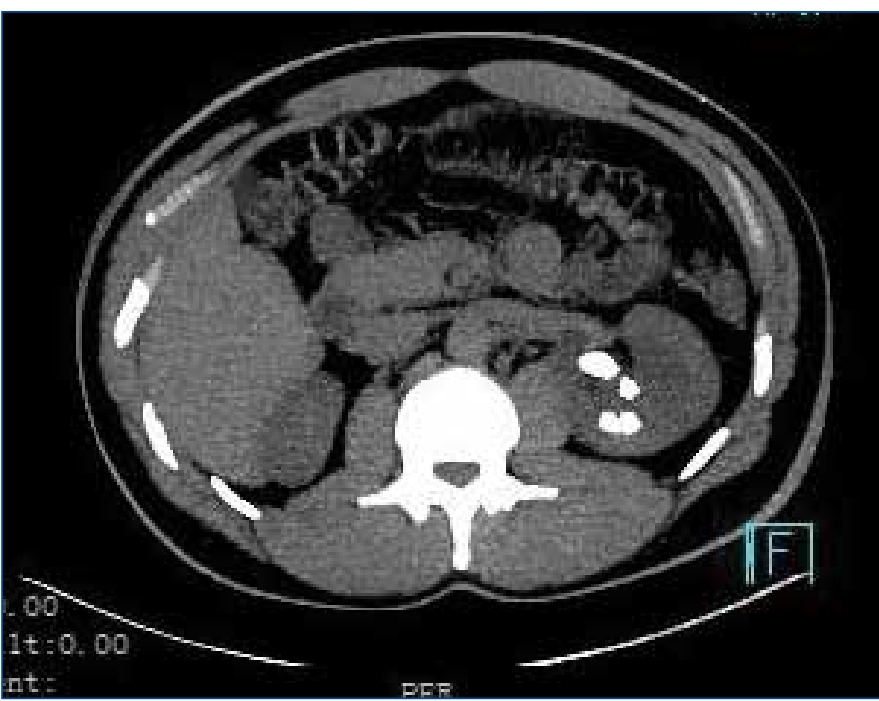

Fig. 1. Preoperative computed tomography scan showing multiple stones in the upper collecting system.

it was extracted intact without any subsequent bleeding. Neither a drain nor a JJ-stent was inserted. Recovery was without incident and he was discharged the next day.

\section{Discussion}

We believe that the present report of a retained, broken nephrostomy catheter that required an interventional management under general anesthesia and, hence, adversely impacted the postoperative course is unique and worth reviewing in several aspects.

There has been no previous report of breakage of a reentry Malecot nephrostomy tube during its early postoperative removal. We had not experienced any difficulty while introducing the tube through the intercostal access puncture and had not applied any undue force on the device during removal. The drainage catheter stayed in place briefly and the patient refused any unintentional tension on the tube. The site of separation was devoid of any evidence of cut, crush, or kinking (Fig. 4). Eventually, we considered this occurrence resulting from an unforeseen malfunction of the device, not consequent to any misuse. The failed device was returned to the manufacturer for analysis.

Although we hadn't encountered any similar report on PubMed, a web search revealed two incidents of broken drainage tubes reported on FDA Manufacturer and User Facility Device Experience (MAUDE) data. MAUDE data represents voluntary and manufacturer reports of adverse events involving medical devices. ${ }^{4}$ In this database, we found reports of two broken re-entry Malecot nephrostomy catheters from the same manufacturer, filed in 2005 and 2014. The adverse events comprised one catheter that snapped at the junction of the tube and the Malecot, during removal 1.5 months after its placement and, second, a nephrostomy

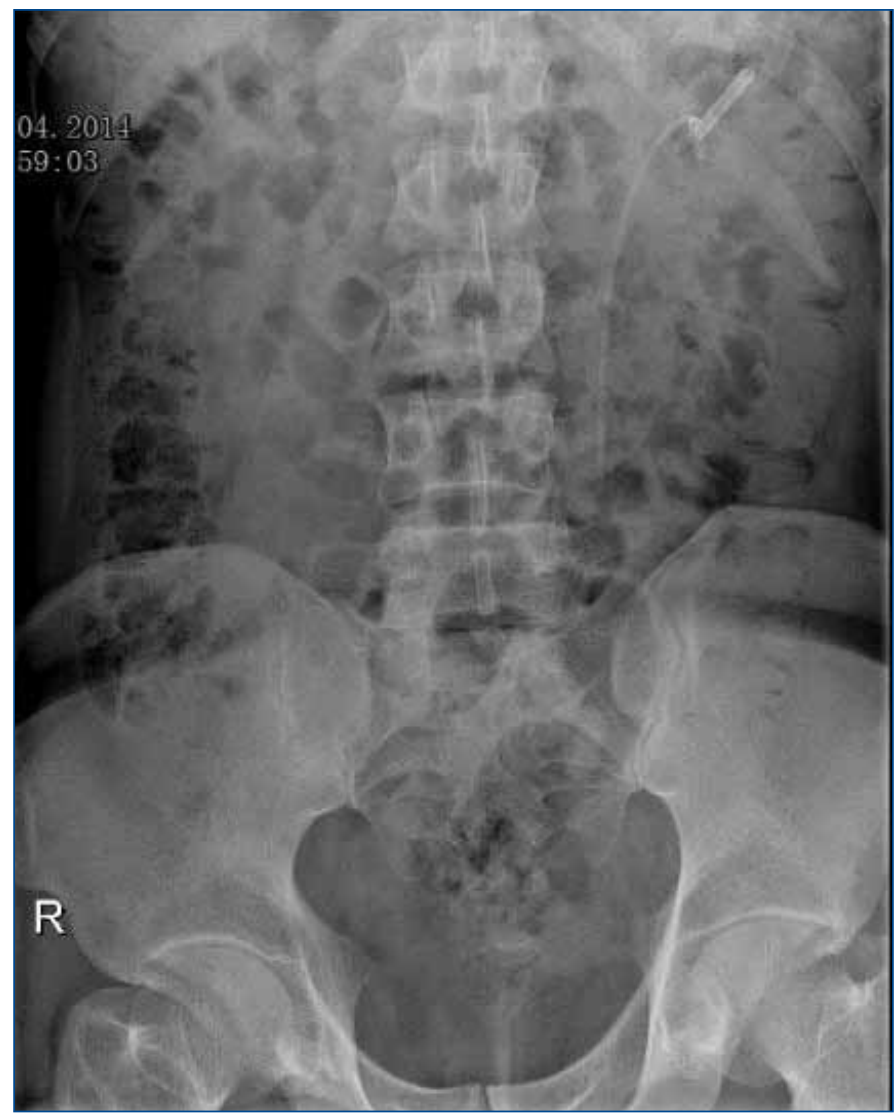

Fig. 2. X-ray film taken just after removal of the broken part of the Malecot nephrostomy tube.

catheter placed one week prior to a second-look PCNL that was found to be dismembered in the retroperitoneum. While the description of the first event did not give details on method of retrieval, the endourological removal of the retained intrarenal part of the device was comprehensively explained in the second report.

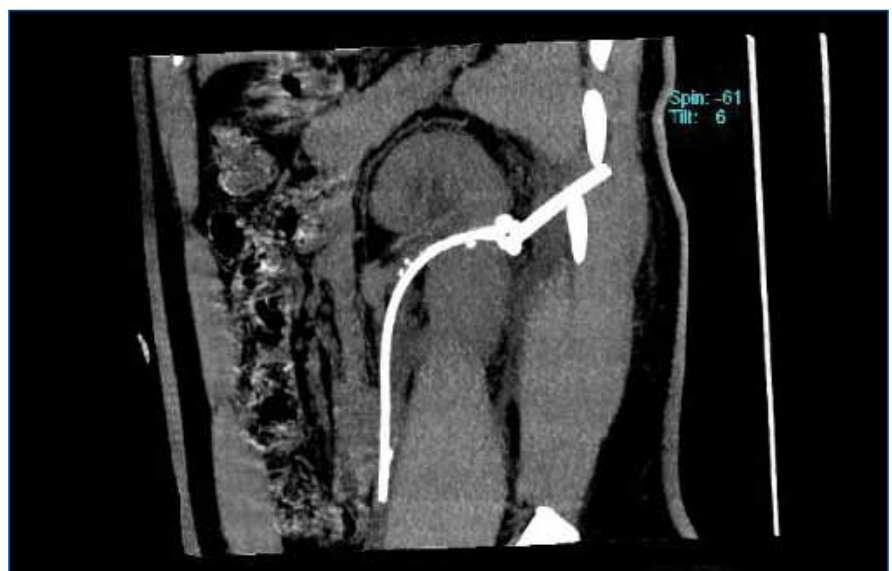

Fig. 3. Computed tomography scan revealing the retained part of the re-entry Malecot nephrostomy catheter. 


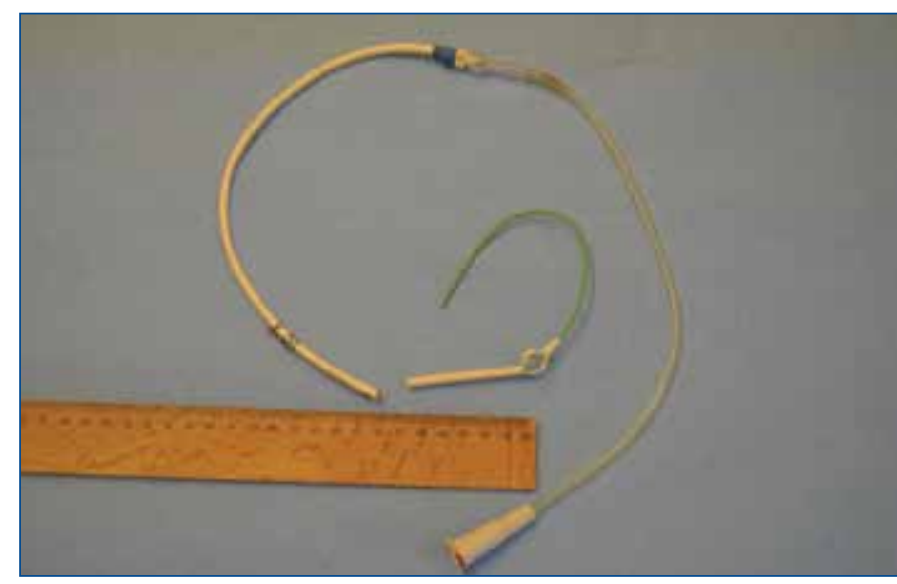

Fig. 4. Broken parts of the extracted nephrostomy catheter.

In our case, the anatomically deep location of the retained segment of the catheter on $\mathrm{CT}$ imaging required an intervention for retrieval under general anesthesia. An open exploration of the wound down to the retroperitoneum was deemed necessary to prevent deeper migration of the catheter and before serious bleeding or urine leakage occurred. The outcome and management of this unavoidable complication scored the operation as Grade IIIb in MCD system, albeit the adverse event was due to a device malfunction and not actually a procedure-related complication.

The Grade III complications are defined as "requiring surgical, endoscopic or radiological intervention, either (a) not under general anesthesia or (b) under general anesthesia." Studies on large patients groups have documented Clavien III complications in $1.3-4.1 \%$ of PCNL. ${ }^{2,5-7}$ Urine leakage and hemopneumothorax are among the more frequent complications that require intervention, whereas uncontrolled bleeding and adjacent organ injuries are the most feared. Rare occurrences, such as entrapped wires or tubes, emigration of dislodged lithotripter fragments, and retention of sheaths have also been reported. ${ }^{5,8,9}$ Although the MDC classification provides an objective, stratified grading system for postoperative complications, some outcomes are still difficult to classify. Several authors have duly drawn attention to the need for a consensus to specify certain complications. ${ }^{2,7,10} \mathrm{~A}$ controversy on whether to include some ancillary treatments as Grade IIla/b complication still exists.

Similar unforeseen problems may occur after a PCNL, when other methods or instruments of drainage are also used. Accidental nephrostomy tube dislodgment or migration of ureteral JJ-stent can complicate the postoperative period. Choi et al compared tubeless PCNL with tethered JJ-stents (aiding easier removal) with $8 \mathrm{~F}$ nephrostomy drainage after PCNL in a randomized comparison study. ${ }^{11}$ They found that JJ-stent dislodgement was seen in $25 \%$ of their patients and exclusively in women. ${ }^{11}$ Patient factors, such as body mass index, distance from skin to the collecting system, and degree of hydronephrosis may influence the likelihood of tube dislodgment, in addition to the factors related to the instrument of drainage.

Bayne et al reported that despite having greater rigidity and a long filiform tip, Malecot reentry tubes did not prevent dislodgment. ${ }^{12}$ The authors have acknowledged that the ideal nephrostomy tube should be durable and able to maintain a stable position within the collecting system; resist kinking in and outside the body; allow for urine, blood/ clots, and stone debris to exit the body; and minimize patient discomfort. ${ }^{12}$

In our case, although not being a life-threatening situation, a device-related complication significantly altered the patient's postoperative course. In this context, we believe it is important to document rare, unstandardized complications, as these examples may add insight to the reporting and scoring methodology.

Competing interests: The authors declare no competing financial or personal interests.

This paper has been peer-reviewed.

\section{References}

1. Seitz C, Desai M, Häcker A, et al. Incidence, prevention, and management of complications following percutaneous nephrolitholapaxy. Eur Urology 2012:61:146-58. http://dx.doi.org/10.1016/i. eururo.2011.09.016

2. de la Rosette J, Assimos D, Desai M, et al. The Clinical Research Office of the Endourological Society Percutaneous Nephrolithotomy Global Study: Indications, complications, and outcomes in 5803 patients. J Endourol 2011;25:11-7. http://dx.doi.org/10.1089/end.2010.0424

3. de la Rosette JJ, Opondo D, Daels FP, et al. Categorisation of complications and validation of the Clavien score for percutaneous nephrolithotomy. Eur Urol 2012:62:246-55. http://dx.doi.org/10.1016/i. eururo.2012.03.055

4. FDA MAUDE. (n.d.). Retrieved from Manufacturer and User Facility Device Experience: http://www. accessdata.fda.gov/scripts/cdrh/cfdocs/cfMAUDE/search.CFM. Accessed February 2, 2016.

5. Shin TS, Cho HJ, Hong SH, et al. Complications of percutaneous nephrolithotomy classified by the modified Clavien grading system: A single centre's experience over 16 years. Korean I Urol 2011;52:769-75. http://dx.doi.org/10.4111/kju.2011.52.11.769

6. Skolarikos A, de la Rosette J. Prevention and treatment of complications following percutaneous nephrolithotomy. Curr Opin Urol 2008;18:229-34. http://dx.doi.org/10.1097/MOU.0b013e3282f46afc

7. Tefekli A, Ali Karadag M, Tepeler K, et al. Classification of percutaneous nephrolithotomy complications using the modified Clavien grading system: Looking for a standard. Eur Urol 2008;53:184-90. http:// dx.doi.org/10.1016/i.eururo.2007.06.049

8. Anderson JK, Monga M. Management of the retained percutaneous nephrostomy catheter. JSLS 2006;10:126-8.

9. Ugras $M$, Gunes $A$, Baydinc $C$. Severe renal bleeding caused by a ruptured renal sheath: Case report of a rare complication of percutaneous nephrolithotomy. BMC Urol 2002;2:10-6. http://dx.doi. org/10.1186/1471-2490-2-10

10. Zuazu JR, Hruza M, Rassweiler JJ, et al. The Clavien classification system to optimize the documentation of PCNL morbidity. Arch Ital Urol Androl 2010;82:20-2.

11. Choi $M$, Brusky J, Weaver J, et al. Randomized trial comparing modified tubeless percutaneous nephrolithotomy with tailed stent with percutaneous nephrostomy with smallbore tube. J Endourol 2006;20:76670. http://dx.doi.org/10.1089/end.2006.20.766

12. Bayne D, Taylor ER, Hampson L, et al. Determinants of nephrostomy tube dislodgment after percutaneous nephrolithotomy. J Endourol 2015;29:289-92. http://dx.doi.org/10.1089/end.2014.0387

Correspondence: Dr. Bora Ozveren, Department of Urology, Acibadem University School of Medicine, Turkey; ozverenb@yahoo.com 